\title{
Improving competitive integrated employment for youth and young adults with disabilities: Findings from an evaluation of eight Partnerships in Employment Systems Change Projects
}

\author{
Kathleen Tucker ${ }^{\mathrm{a}, *}$, Heather Feng $^{\mathrm{a}}$, Cindy Gruman ${ }^{\mathrm{a}}$ and Larissa Crossen ${ }^{\mathrm{b}}$ \\ ${ }^{\mathrm{a}}$ The Lewin Group, Falls Church, VA, USA \\ ${ }^{\mathrm{b}}$ Administration on Intellectual and Developmental Disabilities, Administration for Community Living, U.S. \\ Department of Health and Human Services, Washington, DC, USA
}

Revised/Accepted April 2017

\begin{abstract}
.
BACKGROUND: The eight Partnerships in Employment states each formed a consortium of stakeholders to advance systems change to improve competitive integrated employment outcomes for youth and young adults with intellectual and developmental disabilities. The eight states include Alaska, California, Iowa, Mississippi, Missouri, New York, Tennessee, and Wisconsin.

OBJECTIVE: As the national evaluator, The Lewin Group evaluates the states' progress in achieving their goals. These include enhancing collaborations, developing or changing policies, removing systemic barriers, and implementing strategies and promising practices to support competitive integrated employment.

METHODS: This article provides findings from the evaluation related to the Build Initiative framework's five focus areas of systems change-Context, Components, Connections, Infrastructure, and Scale or Sustainability.

RESULTS: During the five-year grant, each consortium pursued innovative strategies at the state, community, and individual level. These efforts aimed to create better connections, change policies, establish effective programs, create supports, and produce broad impacts to advance systems change supporting youth with disabilities beyond the grant.

CONCLUSIONS: Despite variations in existing state policies and infrastructure, available resources, and agency priorities, promising practices emerged across and within the eight state consortia to improve competitive integrated employment outcomes for youth and young adults with intellectual and developmental disabilities.
\end{abstract}

Keywords: Evaluation, employment, competitive integrated employment, youth, intellectual and developmental disabilities, school to work transition, systems change, build initiative

\footnotetext{
*Address for correspondence: Kathleen Tucker, The Lewin Group, 3130 Fairview Park Drive Suite 500, Falls Church, VA 22201, USA. Tel.: +1 703 269 5752; Fax: +1 7032695501 ; E-mail: Kathleen.tucker@lewin.com.
}

\section{Introduction}

In the decades since the Americans with Disabilities Act (ADA) of 1990, federal and state governments have enacted policies to support individuals with disabilities, including legislation to support the philosophy of employment as the first 
and preferred option for individuals with disabilities. Multiple federal and state systems change initiatives have also focused on increasing competitive integrated employment (CIE) outcomes for individuals with disabilities, including youth and young adults with intellectual and developmental disabilities (I/DD). For many individuals with I/DD, securing and maintaining employment is a key aspect of achieving independence and living a productive life in the community. However, youth and young adults with I/DD often are excluded from general education classrooms, directed to segregated employment settings, and met with low societal expectations for employment. To achieve the ADA goals of ensuring full participation and economic self-sufficiency for all people with I/DD, collaboration needs to be strengthened across local, state, and federal systems. With funding from the Developmental Disabilities Assistance and Bill of Rights Act Reauthorization of 2000 (DD Act) Projects of National Significance, the Administration on Intellectual and Developmental Disabilities (AIDD) established the Partnerships in Employment (PIE) Systems Change Project to enhance collaboration across state systems and improve employment outcomes for youth and young adults with I/DD.

The PIE Systems Change Project is a five-year grant awarded by the AIDD to six states in 2011 (California, Iowa, Mississippi, Missouri, New York, and Wisconsin) and two additional states in 2012 (Alaska and Tennessee). This project promoted cross-systems and cross-agency collaboration to improve CIE outcomes for youth and young adults with I/DD. Each of the eight PIE states were required to form a consortium of stakeholders that represent stakeholders at the individual, community, and state level. With Projects of National Significance funding, the PIE Project supported increased opportunities for involving selfadvocates in state agency systems change initiatives. Specifically, each consortium was required to include a representative from the Developmental Disabilities Agency, Vocational Rehabilitation Agency, State Education Agency, and State Developmental Disabilities Council. To engage broader perspectives, states also invited self-advocates, family members, educators, service providers, employers, legislators, and other agency leaders (e.g., Division of Workforce Development, Medicaid Agency) to participate in monthly, quarterly, and semi-annual consortium meetings. Due to state-specific political, economic, and social environments, each state targeted different areas of the system to improve employment outcomes. To understand these similarities and differences, the AIDD awarded a six-year evaluation contract to The Lewin Group. The Lewin Group developed and implemented a process and systems change evaluation of the eight projects.

All eight states recognized that employment for people with disabilities remains significantly lower than for people without disabilities. At the onset of this project in 2011, the national employment rate in the United States for working-age adults (16 to 64 years old) with a disability was 32.6 percent $(22.3$ percent with a cognitive disability) compared to 70.7 percent for people without a disability (Erickson, Lee, $\&$ von Schrader, 2016). Looking specifically at the I/DD population nationwide, participation in integrated employment has remained constant around 19 percent from 2011 through 2014 (Statedata.info, 2016). While research supports work-based educational opportunities for youth and young adults with I/DD, available opportunities for competitive integrated work experiences varies by state (Test, 2009b). In 2011, participation in integrated employment services provided by state I/DD agencies varied widely across states from one percent in Hawaii to 88 percent in Washington state (Butterworth, 2015). Facilitybased and non-work experiences continue to make up the largest percentage of individuals with I/DD served by state I/DD agencies. In 2011, the majority of individuals with I/DD served by state I/DD agencies were participating in facility-based work (26 percent) or not working (41 percent in facility-based non-work, 45 percent in community-based non-work) (Butterworth, 2015).

States also recognized the importance of youth and young adults with I/DD seeking to enter the workforce having past work experiences. Research indicates that work experience and competitive integrated employment during high school is a strong predictor for successful post-school employment (Carter, Austin, \& Trainor, 2012). Specifically, if a young person with I/DD has one work-based experience in high school, the chances for employment double, and if a young adult with I/DD has two work-based learning experiences, his or her chances for employment are five times that of a young adult with I/DD with no work-based learning experiences (Test, 2009a). While attaining post-secondary education generally leads to better employment outcomes, individuals with I/DD exiting school often have little planning for transition from school to work or post-secondary education (The Arc, 2015). Each consortium recognized the significance of work- 
based learning experiences and set out to reduce the employment gap, improve early work opportunities for transition-aged youth with I/DD, and increase knowledge and awareness of employment opportunities.

Developing a shared vision was the next step towards cross-system and cross-agency collaboration. Early in the project, each state consortium identified common barriers to employment in their state for youth with I/DD and developed shared goals and definitions of CIE. Based on these early discussions, it was clear that employment was defined differently depending on the state agency, community member, or individual. The common definition for competitive integrated employment used across the project is "part- or full-time work performed by an individual which is compensated by at least minimum wage under the Fair Labor Standards Act; is located where the employee interacts with other individuals who do not have disabilities; and is given an opportunity for advancement similar to those for other nondisabled peers in similar positions" (Public Law, 2014).

During the five-year project, state consortia pursued activities related to the project objectives. Project objectives include: (a) Developing or Changing Policies to Support CIE, (b) Removing Systemic Barriers to CIE, (c) Building Cross-System and Cross-Agency Collaboration, and (d) Implementing Strategies and Exploring and Scaling-Up Promising Practices to Improve CIE Outcomes. To meet these objectives, state consortia identified and implemented best practices, such as legislation supporting the Employment First philosophy; educational materials, trainings, and Community Conversations to engage stakeholders, build capacity, and raise expectations; and shared data tools to increase access to employment data. States also worked to increase awareness of employment opportunities among individuals with I/DD, family members, employers, educators, state legislators, and other community members. Based on available resources and state priorities, the focus varied each year, but overall, states consistently worked to improve cross-system and cross-agency collaboration. A key outcome from this project across all states was improved relationships at all levels between individuals with I/DD and their family members, educators, service providers, employers, and state agency leaders. The consortia also identified key opportunities to sustain and continue the work towards enhancing state systems that support CIE. By focusing on youth and young adults with disabilities transitioning from school to post-secondary education and employment, the AIDD and the PIE states are preparing individuals with I/DD to lead a selfsustaining life for current and future employment.

Through the PIE Systems Change Project, the AIDD envisioned improving post-school outcomes, including economic self-sufficiency, independent living, and the opportunity to live a self-determined life for youth and young adults with I/DD, regardless of the intensity of his or her needs. This article highlights The Lewin Group's evaluation findings from October 2011 through September 2016. Federal funding for six of the eight states ended in September 2016. Of the states ending in 2016, four states requested and received a no-cost extension ranging from three to twelve months. Funding for the two remaining states ends in September 2017. The PIE Systems Change Project involves multiple stakeholders, requires coordination across programs and agencies, utilizes unique public funding sources, and changes and/or modifies multiple systems at different stages of development. Since systems change projects may take many years to observe and quantify the intended impact, the strategies used by each state constantly evolve in response to the political, economic, and social contexts. To account for the specific areas states aimed to improve or change, The Lewin Group has evaluated state efforts related to five focus areas of systems change under the Build Initiative framework-Context, Components, Connections, Infrastructure, and Scale or Sustainability (Coffman, 2007).

\section{Method}

\subsection{Research questions and evaluation framework}

The Lewin Group used data contributed by the PIE states and the Build Initiative framework to conduct a national evaluation and answer the AIDD's research questions. The evaluation addressed the AIDD's research questions: (1) What aspects of systems change did the PIE Project intend to effect; (2) What changes to policies and practices are associated with the PIE Project; (3) What implementation strategies are related to program outputs and outcomes; and (4) What components are necessary to create CIE opportunities at the state and local level? This article provides qualitative findings from the evaluation related to the Build Initiative framework's five focus 
areas of systems change. For the PIE evaluation, the five focus areas of systems change are defined below.

- Context: Improving the environment that surrounds the system so it produces the policy, funding, and social changes needed to create and sustain improved CIE outcomes.

- Components: Establishing high-performing programs and services within the system that results in positive CIE outcomes for youth and young adults with I/DD.

- Connections: Creating strong and effective linkages across system components that further improve CIE outcomes for youth and young adults with I/DD.

- Infrastructure: Developing the ongoing support systems need to function effectively and with quality.

- Scale or Sustainability: Ensuring a comprehensive system is available to all youth and young adults with I/DD to produce broad and inclusive CIE outcomes.

Based on these definitions, The Lewin Group's evaluation framework aligned the AIDD's research questions, project objectives, and five focus areas. Each objective informed or addressed at least one research question and one primary focus area, with all objectives informing Research Question \#4 and the Scale or Sustainability focus area.

Early in the project, themes emerged for how states intended to achieve systems change, and The Lewin Group identified the Build Initiative framework as a model for its evaluation of the PIE states' progress to meet project goals and objectives, which included changing policies, improving state programs, building cross-system and cross-agency collaboration, and scaling-up or sustaining best practices. The project objectives aligned closely with the Build Initiative's five focus areas of systems change: Context studies states' steps to change policies, Components focuses on states' work to improve state programs and remove systemic barriers, Connections examines how states built cross-system and cross-agency collaboration, and Infrastructure and Scale or Sustainability considers how states approached scaling-up or sustaining best practices. While the basic framework developed by Julia Coffman (2007) suggested a linear progression moving from Context to Components, Connections, Infrastructure and finally to Scale, the framework used by The Lewin Group also emphasized that systems change initiatives could focus on multiple areas simultaneously and in any order. Since each PIE state simultaneously worked on changing policies, supporting employment programs, building relationships with agency leaders, as well as planning for sustainability beyond the grant, The Lewin Group modified the Build Initiative framework to suggest a non-linear progression. This assumed a state might focus additional attention on one or more areas depending on the priorities of the state and the resources and opportunities available at that time. Thus, The Lewin Group's evaluation did not require a state to complete activities or outcomes in a linear sequence, but instead could move between focus areas in any order or direction at any given time.

\subsection{Data collection and analysis}

The combination of qualitative, quantitative, and observational data provided a comprehensive understanding of state activities, outputs, and outcomes towards transforming state systems to increase CIE. While the observational data was gathered during in-person site visits, The Lewin Group collected qualitative and quantitative data through semi-annual web-based reports. The Lewin Group convened two Technical Working Group meetings in 2012 to review and finalize the data elements for the evaluation. The Technical Working Group included ten individuals representing providers, policy makers, self-advocates, educators, employers, and other stakeholders. In total, the evaluation included analysis of the qualitative, quantitative, and observational data from nine semi-annual reporting periods, state updates on the monthly PIE Network meetings facilitated by the project's technical assistance provider, quarterly check-ins with states led by The Lewin Group, and three site visits to each state during the grant period.

The Lewin Group entered qualitative data from the semi-annual web-based reports into ATLAS.ti software to facilitate the coding and organization of data, and expedite retrieval of information (Scientific Software Development GmbH, 2016). ATLAS.ti software not only houses qualitative data (organized deductively, by research question or domain) but also uses inductive codes that emerge directly from responses. Higher-level codes (i.e., primary codes) were identified that represent themes across the five focus areas and themes unique to a specific focus area (e.g., for infrastructure, shared data tools). The code list followed a similar structure to the Results section's structure with the five focus areas of systems change and sub-topics. For example, Context was the primary 
code and sub-codes included policy collaboration, funding regulations or legislation, other federal initiatives, and Employment First-related activities. The Lewin Group used ATLAS.ti to code for quantifiable information within the submitted data, such as the number of meetings held, number of individuals attending the training, and number of individuals employed in integrated settings. The Lewin Group used Microsoft Excel for its descriptive statistical analysis to present key numeric findings in tables and charts to the AIDD.

Since systems change does not occur in isolation, many activities or outcomes may have been accomplished with or without grant funding. As a result, distinguishing which activities or outcomes resulted directly from PIE and which activities occurred in parallel with PIE has been a major challenge for state-level reporting requirements.

\section{Results}

During the five-year project, the eight PIE states continued to pursue efforts to improve the employment outcomes for youth and young adults with I/DD within each of the five focus areas-Context, Components, Connections, Infrastructure, and Scale or Sustainability. Results of the state activities and The Lewin Group's data collection and analysis are grouped below by theme into each category of the Build Initiative framework. The following sections define and contextualize each category of the Build Initiative framework, list general activities that states pursued to achieve outcomes within each category of the framework, and highlight state-specific examples.

\subsection{Context}

The ability of a state to improve CIE outcomes for youth and young adults with I/DD depends on the state's political, economic, social, or cultural contexts and accordingly, the federal and state policies that shape these contexts. Before PIE states passed legislation or enacted policies supporting CIE, many state policies supported segregated, subminimum wage work and did not reimburse for employment services. State policies that did not prioritize CIE created environments that made CIE difficult to attain for individuals with I/DD.

To create environments that promote CIE, PIE state consortia worked to develop or improve employment-focused policies. These policies priori- tize CIE over subminimum wage work and sheltered workshops, and establish funding or funding sources for employment services and CIE-focused initiatives. Thus, these policies also gave legislative authority to and provided direction and context for states' efforts towards systems change. Activities to promote employment-focused policies addressed the PIE objective Developing or Changing Policies to Support Integrated Employment. These activities included both developing legislation or state plans from federal policies or regulations such as policies supporting the philosophy of Employment First, the Workforce Innovation and Opportunity Act (WIOA), the Achieving a Better Life Experience (ABLE) Act, or the Home and Community-Based Settings (HCBS) Rules; and developing policies or regulations at the state level.

\subsubsection{Policies supporting CIE: Spotlight on Employment First philosophy}

Of the many activities that state consortia pursued to support systems change, states consistently identified strategies supporting the philosophy of Employment First. According to the U.S. Department of Labor, Office of Disability Employment Policy (ODEP), Employment First is a systems change framework that recognizes all individuals as capable of full participation in integrated employment and community life (U.S. Department of Labor, 2016). The Employment First philosophy is a statement of intent that evolved from grassroots state efforts. Based on these efforts, ODEP adopted the Employment First framework and encouraged states and other public systems to align policies, legislation, and systems change efforts with Employment First. This alignment results in a commitment to integrated employment as the preferred outcome of employment and other services for individuals with I/DD. Despite the uniform presence of Employment First-oriented activities in each PIE state, state consortia approaches to and outcomes from their efforts to align their state policies with Employment First philosophies varied. The following sections highlight some examples of state approaches to adopting Employment First policies.

3.1.1.1. Alaska, California, and Mississippi's Employment First legislation. Alaska, California, and Mississippi consortia conducted legislative advocacy work to further Employment First policies and legislation within their states. To accomplish these outcomes, each of these states' consortia 
forged connections with and engaged legislators, and provided testimony to the state legislature. State consortia each drafted recommendations based on research, led presentations and disseminated resources, and engaged legislators and other stakeholders directly to understand and alleviate their concerns.

In 2013, the Alaska Governor's Council on Disabilities and Special Education, the lead entity for the Alaska Integrated Employment Initiative (AIEI) consortium, adopted an Employment First policy. Members of AIEI identified a legislative representative that would sponsor Employment First legislation, and worked closely with the representative's staff to draft legislation for the 2014 legislative session. At the same time, AIEI members worked to engage stakeholders and educate legislators to gain public and legislative support. AIEI members led presentations and met with stakeholder organizations, including the Alaska Association of Developmental Disabilities, employers, and state agency leaders to understand and address their concerns. Members of AIEI also researched states that had passed Employment First-related policy, and held teleconferences with these states' leadership to develop a legislative packet. The bill's sponsor used the packet to garner additional co-sponsors in the House of Representatives, obtain a Senate companion bill sponsor, and recruit Senate bill co-sponsors. The House and Senate bills passed unanimously and were signed into law by the Alaska governor in May 2014. Throughout the process, AIEI's emphasis on and commitment to identifying and recruiting key legislative sponsors, and engaging public stakeholders were critical to the bill's passage. Specifically, the identification of a legislative sponsor and working with the sponsor's team ensured that the bill-drafting process included legislative law writers that could edit the bill, and that the bill was pre-filed at the start of the legislative session. AIEI's advocacy and stakeholder engagement efforts helped the bill gain public support.

California's efforts to provide testimony to the legislature, collaborate with legislators, and gather strong stakeholder support through cross-disability partnership were pivotal in the passage of the state's Employment First bill in 2013. In addition to passing state policy, California also focused on local implementation of Employment First policies. Thirteen Division of Developmental Disabilities Agencies' Regional Centers have adopted and are implementing their own Employment First policies. Participation in the California consortium, California Employ- ment Consortium for Youth (CECY), inspired several Regional Centers to move forward with implementing change in their region. Implementation of Employment First policies at the regional level focused on vendor buy-in, ending new admissions to sheltered work, capacity building training and professional development, strong interagency collaboration, and information and supports for families.

Mississippi's consortium, Mississippi Partnerships for Employment for Youth and Young Adults (MSPE), also focused on advocacy and awareness efforts, hosted awareness sessions, disseminated resources, and met with agency leaders and legislators. During the Disability Employment Partnerships Awareness Day at the Capitol in January 2014, the Governor signed an Executive Order that reactivated a Disability Resource Commission. With support from a legislative champion, legislation with Employment First language passed unanimously in the House but did not move out of Senate committee. In 2014, MSPE managing partners submitted a letter to the Governor requesting appointments to the Disability Resource Commission. Legislation was introduced again in 2015 and the Governor signed the Mississippi Competitive Employment Act in April 2015.

\subsubsection{Employment First Executive Orders, com-} missions, and task forces in Mississippi, New York, and Tennessee. Prior to passing the state's Competitive Employment Act, Mississippi advocated for its governor to sign an Employment First Executive Order. New York and Tennessee's governors also signed Employment First Executive Orders to promote Employment First within their states. In all three states, the Employment First Executive Orders created Employment First-oriented task forces or commissions charged with promoting Employment First policy within their states. These commissions wrote reports and provided recommendations for legislators and state governors, and established networks and other groups that would benefit the employment landscape.

\subsubsection{State policy work}

States also worked to make their political, economic, social, or cultural contexts more favorable to systems change by revising or developing policies at the state agency level. State-level policies developed included changing Medicaid reimbursement or payment structures to encourage employment supports or remove incentives for segregated employment, revising eligibility requirements or application 
protocols for Medicaid to expand access to employment supports for youth with $\mathrm{I} / \mathrm{DD}$, and shifting education policy to support employment preparation. The section below highlights Iowa's rate restructuring work as an example of state policy work to restructure reimbursement rates, and overcome barriers to employment.

\subsubsection{Iowa's rate restructuring work. Iowa's PIE} consortium titled Iowa Coalition for Integrated Employment (ICIE) focused much of its policy change efforts on restructuring its Medicaid rate reimbursement structures to better support individuals seeking employment. Before ICIE and the state's efforts, Iowa's reimbursement rates for employment services were frequently lower than the actual cost of the services, which caused many providers to either reduce or remove career placements from services offered.

To advocate for and recommend ideas for a revised reimbursement structure that would support employment, ICIE gathered and shared member feedback with the Iowa Medicaid Enterprise and Iowa Vocational Rehabilitation Services (IVRS). This work integrated resources across Iowa initiatives by combining recommendations from a funding analysis and input from a stakeholder retreat developed as part of Iowa's membership in the State Employment Leadership Network (SELN). ICIE members also provided input on Medicaid rate restructuring during five community forums held across the state. Additionally, ICIE's Funding and Policy Workgroup and Iowa's Department of Health Services (DHS) Employment Services Redesign Workgroup collaborated to develop a funding transition model for rate restructuring purposes.

ICIE also began developing advocacy techniques as the new reimbursement rules were being drafted so that the rules would garner robust legislative attention. As part of ICIE's advocacy plan, a memorandum of talking points was issued as a resource for advocates contacting legislators and the governor. ICIE members also called DHS Administrators and attended Mental Health and Disabilities Services Commission meetings during the rules' public comment periods to provide input. ICIE members, providers, and family members of individuals with I/DD used these meetings as an opportunity to learn about the rules.

The final rules package went into effect in May 2016. Similar to the states that engaged legislators and stakeholders to create support for federally based policies, ICIE found that continued interaction with legislators and other stakeholders was valuable in creating support for the rules package.

\subsubsection{Providing financial support for post-} secondary education students in Tennessee. TennesseeWorks engaged in advocacy work that resulted in the Tennessee Department of Human Services (DHS) changing policies to provide financial support for eligible students in Tennessee's post-secondary programs, and also the passage of legislation establishing the STEP UP scholarship program for post-secondary students with an intellectual disability (Tennessee Student Assistance Corporation, 2016). In 2014, DHS released a memorandum to the Tennessee Division of Rehabilitation Services staff and Post-Secondary Education Alliance Tennessee regarding the availability of financial support for Vocational Rehabilitation-eligible students participating in Post-Secondary Education Alliance programs. This availability of financial assistance, in combination with scholarship support established by the STEP UP legislation (2013 and 2014) and Pell Grant assistance, made post-secondary education an option for young adults with disabilities in Tennessee.

\subsection{Components}

The PIE states' work to improve their environments through policy change complemented their work to establish programs and services to support individuals with I/DD. Improving environments for systems change meant that it would become possible to establish and implement components within those environments - namely, programs and services. These programs and services are also necessary because they directly support individuals with I/DD; and help educators, employment support providers, employers, and other stakeholders adapt to policy change. State activities to establish programs and services addressed the PIE objective Removing Systemic Barriers to CIE.

Through the grant period, states established many programs and services to remove systemic barriers to CIE. Just as their states' policies, programs, and services varied, consortia activities differed accordingly. However, state activities to establish programs and services generally fall under several categories, including establishing model demonstration projects to support early work experience and establishing secondary and post-secondary education-related programs. In addition, states participated in capacity 
building activities, which included trainings for benefits counselors in Alaska and New York; trainings for community rehabilitation service providers in Iowa; and general trainings to build capacity in state agencies and schools in all states. Alaska, New York, and Tennessee also worked to improve existing programs by developing alternative certificates to support school-based employment readiness and career training. The sections below highlight just a few of many categories of programs and services supported by state consortia.

\subsubsection{Statewide model demonstration project sites}

In six of the eight projects, states implemented model demonstration sites that provided students with opportunities to gain job experience and training that would help them obtain employment. The remaining two states pursued other opportunities to engage individuals with disabilities. These pilot sites varied in their design: Mississippi, Missouri, and Wisconsin issued requests for proposals from potential pilot sites; New York worked with and modified an existing national model; and California selected sites based on their existing achievement of employment in CIE outcomes for individuals with I/DD. Iowa had two different model demonstration projects. For the first, the state selected school team sites based on performance indicators from Iowa Vocational Rehabilitation Services and Department of Education data; and for the second, the state collaborated with the Employment First State Leadership Mentoring Program (EFSLMP) to fund model service provider projects. While the majority of the 50 project sites in the six states served as demonstration programs that focused on local impact and future scalability, the sites also identified barriers to CIE and policy change. The states and their model demonstration projects are listed in Table 1.

\subsubsection{Mississippi's request for proposals to estab-} lish pilot sites. The MSPE established pilot programs by issuing a request for proposals and ultimately providing funding to four pilot sites, three of which were active from 2012 to 2015. For the duration of the pilots, the Mississippi Council on Developmental Disabilities provided administrative oversight to pilot projects. These projects demonstrated how schools could improve transition services, provide students with employment experiences, and ultimately help students find competitive employment in the community. For example, one of MSPE's school-based pilot sites featured a community-based coffee shop where students with disabilities learned work and social skills, while another featured community-based work and a greenhouse.

At the end of pilot site funding, three pilot sites had trained 70 students in employment skills training programs and had assisted 55 students to find employment from 25 employers. Though funding for the pilots ended, MSPE continues to work with two school districts to develop an implementation guide for statewide distribution that shows how to replicate pilot results.

\subsubsection{Sustaining and scaling-up pilot sites' best} practices through Wisconsin's coaching model. Wisconsin's consortium, Let's Get to Work (LGTW), also established pilot sites through a request for proposals. LGTW ultimately established five Round 1 pilot schools and four Round 2 pilot schools. LGTW pilot schools received training from two coaches to help plan their interventions, collect baseline data, and identify their current strengths and areas for improvement. The coaching team drew upon their experiences to create a comprehensive, user-friendly set of tools and strategies called the LGTW Quick Guide on Transition to Employment. The guide provides best practices, strategies, tips, and resources to help schools increase their employment and overall transition outcomes (Wisconsin Board for People with Developmental Disabilities, 2016). Most of the topics were created because the coaching team found these areas to be particularly challenging.

LGTW pilot sites' accomplishments included tripling the number of LGTW students with paid jobs in their community after one year from 5 to 18 students, increasing the percentage of LGTW students working in paid positions after three years to 66 percent, and doubling the number of employers hiring LGTW students. The pilots' best practices also proved to be scalable, as the success of LGTW pilots led Wisconsin's Promoting Readiness of Minors in Supplemental Security Income (PROMISE) project team to adopt the LGTW Quick Guide and promising practices from the pilot sites. Additionally, Wisconsin's Transition Improvement Grant (TIG) schools, which had some of the same partners and coaches as the LGTW pilot sites, also used the LGTW Quick Guide and committed to using LGTW promising practices.

LGTW also conducted further best-practice dissemination activities, including co-hosting a Community Based Integrated Employment Summit that 
Table 1

Partnerships in employment project name, number of model demonstration project sites, and years active by state

\begin{tabular}{|c|c|c|c|c|}
\hline State & Consortium Name & $\begin{array}{l}\text { Model Demonstration } \\
\text { Project Site Name }\end{array}$ & $\begin{array}{l}\text { Total Number } \\
\text { of Sites }\end{array}$ & $\begin{array}{l}\text { Years Sites } \\
\text { Active }\end{array}$ \\
\hline Alaska & $\begin{array}{l}\text { Alaska Integrated Employment Initiative } \\
\text { (AIEI) }\end{array}$ & Not applicable (N/A) 2012 grantee & N/A & N/A \\
\hline California & $\begin{array}{l}\text { California Employment Consortium for } \\
\text { Youth (CECY) }\end{array}$ & $\begin{array}{l}\text { Local Employment Collaborative Teams } \\
\text { (LECTs) }\end{array}$ & 7 & 2012-2014 \\
\hline \multirow[t]{2}{*}{ Iowa } & \multirow{2}{*}{$\begin{array}{l}\text { Iowa Coalition for Integrated Employment } \\
\text { (ICIE) }\end{array}$} & Model Employment Transition Sites (METS) & 5 & \multirow[t]{2}{*}{ 2012-2016 } \\
\hline & & $\begin{array}{l}\text { Community Rehabilitation Service Providers } \\
\text { (CRPs) }\end{array}$ & 7 & \\
\hline Mississippi & $\begin{array}{l}\text { Mississippi Partnerships for Employment } \\
\text { (MSPE) }\end{array}$ & $\begin{array}{l}\text { Mississippi Partnerships for Employment for } \\
\text { Youth and Young Adults: Building } \\
\text { Opportunity for Learning and Transition } \\
\text { Success (BOLTS), Gathering Grounds, } \\
\text { The Arc of Mississippi Customized } \\
\text { Employment }\end{array}$ & 3 & 2012-2015 \\
\hline Missouri & Show-Me-Careers & Show-Me-Careers Pilot Communities & 8 & 2013-2016 \\
\hline \multirow[t]{2}{*}{ New York } & \multirow{2}{*}{$\begin{array}{l}\text { New York State Partnerships in Employment } \\
\text { (NYS PIE) }\end{array}$} & Employment Training Program & 4 & 2012-2016 \\
\hline & & New York State PIE Project SEARCH ${ }^{\mathrm{TM}}$ & 7 & \\
\hline Tennessee & TennesseeWorks Partnership & N/A 2012 grantee & N/A & N/A \\
\hline Wisconsin & Let's Get to Work & Let's Get to Work Pilot Sites & 9 & $2012-2015$ \\
\hline
\end{tabular}

included LGTW pilot school sites. This Summit was an opportunity to help the five new TIG schools get started on improving their transition outcomes. Teachers, parents, students, and administrators from the LGTW pilot school sites shared their experiences participating in the project, including how they achieved outcomes and how their schools have changed their culture and improved CIE. LGTW coaches also shared the LGTW Quick Guide with TIG schools and other LGTW consortium members.

\subsubsection{Re-tooling a pre-existing framework to cre-} ate model demonstration projects in New York. New York State Partnerships in Employment (NYS PIE) took a different approach compared to other states' consortia in that the state's two pilot models were based on pre-existing frameworks, including the Employment Training Program and Project $\mathrm{SEARCH}^{\mathrm{TM}}$. The New York Office for People with Developmental Disabilities (OPWDD), a NYS PIE partner, expanded the high school Employment Training Program to four additional sites as part of NYS PIE. The Employment Training Program focused on work-readiness school-based curriculum along with paid internship opportunities paid for by OPWDD within the community. NYS PIE leveraged Project SEARCH ${ }^{\mathrm{TM}}$,s pre-existing framework to explore and expand on ways to provide critical job experience and training through a one-year transition services program. NYS PIE took this approach in part because as an already established model, Project SEARCH ${ }^{\mathrm{TM}}$ was tested and known among stakehold- ers. The New York grant recipient, the University of Rochester Strong Center for Developmental Disabilities is also the statewide coordinator for Project $\mathrm{SEARCH}^{\mathrm{TM}}$, and thus collected and tracked longitudinal outcome data for the seven NYS PIE Project $\mathrm{SEARCH}^{\mathrm{TM}}$ pilot sites alongside the original New York State Project SEARCH ${ }^{\mathrm{TM}}$ sites. Preliminary analysis of statewide Project SEARCH ${ }^{\mathrm{TM}}$ data collected in January 2016 indicated that the employment rate of 2015 graduates was approximately 60 percent.

\subsubsection{Post-secondary education}

Some state consortia also worked to improve their states' post-secondary education programs. The states identified a lack of awareness of post-secondary educational opportunities in colleges and universities for students with I/DD as preventing students from earning post-secondary degrees and attaining that qualification for CIE. To raise awareness for these programs, PIE states provided trainings, presented at conferences, and expanded post-secondary career programs for youth. Additionally, PIE states, including California, Mississippi, Tennessee, and Wisconsin, provided support for the expansion and creation of post-secondary educational programs for university students seeking special education degrees or other graduate certificates. Other initiatives increased access to post-secondary educational courses. Missouri also created the Propel program, a new 2-year certificate program for college students with I/DD at the University of Missouri Kansas City. Below are some highlighted examples of how Cali- 
fornia improved post-secondary education outcomes for students with I/DD.

\subsubsection{Expanding post-secondary education} options in California. In California, post-secondary education options improved through the expansion of the state's College2Career Program, which offers students with I/DD greater opportunities to pursue post-secondary education. The lead entity of the CECY, the Tarjan Center, led evaluation efforts to determine employment metrics related to the program. These metrics included the existence of certificate programs in community colleges, types of jobs, and length of employment. A review of the data collected from 2011 to 2014 across five College2Career sites indicated course enrollments were increasingly in integrated settings with a greater proportion of those enrollments relating to students' career goals. Over the course of the project, the number of Department of Rehabilitation-funded College2Career programs increased from five to eight sites. The Department of Rehabilitation will continue to fund eight programs beyond the grant and the California Community College Chancellor's Office will continue to provide technical assistance and support the evaluation of the programs.

\subsection{Connections}

When asked, all state consortia responded that the connections forged during the grant were both some of the most valuable outcomes of their PIE work, and some of the most integral factors that contributed to their successes. By including representatives from multiple state agencies and other organizations, as well as self-advocates, PIE consortia were collaborative by design and naturally facilitated strong connections between its members and members' organizations and agencies. Each state consortium included representatives from the state's Developmental Disabilities Agency, Vocational Rehabilitation Agency, State Education Agency, and State Developmental Disabilities Council; as well as self-advocates, educators, family members, employers, service providers, and other agency leaders.

State consortia also recognized the importance of continuing to identify and engage relevant stakeholders, and further building connections so that their activities would have public support and tangible impact. Therefore, consortia engaged and forged connections with stakeholder groups that would be interested in and impact the employment landscape, including families of individuals with I/DD, businesses, and youth themselves. Consortia activities related to building connections and engaging stakeholders fall under the PIE objective Building Cross-System and Cross-Agency Collaboration. In all of the examples highlighted below, state consortia found leveraging or braiding existing relationships and collaborating with partners critical in establishing new relationships and engaging stakeholders.

\subsubsection{Engaging family members of individuals with $I / D D$}

Several PIE states identified that individuals with I/DD and family members often had low expectations and limited knowledge about available CIE opportunities. To dispel misunderstandings and raise family expectations for their youth, PIE consortia engaged parents and families of youth with I/DD through various methods, including through surveys, trainings, and parent and family groups. Consortia also braided other grants, such as working with subject matter experts from the EFSLMP to engage family members and establish Parent and Family Coalitions in Iowa and Tennessee. The sections below highlight examples of each of these approaches.

3.3.1.1. Collecting surveys to understand and influence parents' expectations in Tennessee. Tennessee's PIE consortium, TennesseeWorks, developed the Family Expectations Survey in 2014 to understand family expectations related to employment and community engagement, and share family perspectives with policymakers and other stakeholders. TennesseeWorks recognized the importance of collecting diverse responses, and therefore collaborated with Tennessee Disability Pathfinder and the Multicultural Outreach Program to reach Spanishspeaking community members. TennesseeWorks worked with these groups to translate the survey into Spanish.

TennesseeWorks exceeded its goal for responses, and received over 2,400 responses in total. Based on these results, TennesseeWorks developed an infographic that advocates shared with legislators at the 2014 Disability Day on the Hill and included in the 2014 Governor's Employment First report. The infographic shows information such as that " 83 percent of families consider some type of employment in the community to be important," and "75 percent of families consider some type of post-secondary 
education to be important." TennesseeWorks also completed analysis of the survey and drafted reports of the survey results. TennesseeWorks included data from the survey on the TennesseeWorks website's Employment and Disability by the Numbers data dashboard (Vanderbilt Kennedy Center for Excellence in Developmental Disabilities, 2016). This data provides insight into Tennessee's employment landscape, and suggests possible pathways for making change.

\subsubsection{Creating Parent and Family Coalitions to} engage families in Iowa and Tennessee. Iowa and Tennessee also created Parent and Family Coalitions to learn how to best support families and their youth with I/DD. In particular, Iowa identified low family involvement from some of the state's PIE Model Employment Transition pilot sites. To increase family involvement, ICIE worked with an EFSLMP subject matter expert to begin a Parent/Family Coalition. Beginning with 10 members in 2013, the Parent/Family Coalition's membership increased to 87 members in 2016. The Parent/Family Coalition provided regular communication, information, support, and advocacy resources for parents and families. As part of its no-cost extension work, ICIE will continue to support the Parent/Family Coalition and assist with identifying parent and family leaders to take over managing the coalition.

\subsubsection{Creating resources to support families} in Missouri. The Missouri consortium, Show-MeCareers, collaborated with the Missouri Family-toFamily Resource Center and the National Supporting Families Community of Practice to develop family support resources. The LifeCourse Tools assist families and individuals with disabilities discover what it takes to navigate life stages (i.e., infancy, early childhood, school age, transition, adulthood, and aging) and life domains (i.e., daily life and employment, community living, safety and security, healthy living, social and spirituality, citizenship and advocacy) (University of Missouri Kansas City Institute for Human Development, 2016). One of these tools was the LifeCourse Daily Life and Employment Guide, which was tested in two of the state's Show-Me-Careers Pilot Communities in 2014. Show-Me-Careers and the Missouri Family-to-Family Resource Center have collectively disseminated 6,180 copies of the Guide between September 2015 and September 2016.
In fall 2014, Show-Me-Careers also worked with two Pilot Communities to develop and implement community level plans to improve family engagement. In 2015, Show-Me-Careers collaborated with the Missouri Developmental Disabilities Council and the National Alliance on Mental Illness to develop a workshop for self-advocates and their families related to asset development. Over 70 participants attended the workshop, which discussed topics including social security benefits and financial education.

\subsubsection{Business engagement efforts}

PIE states also recognized that engaging businesses, changing businesses' expectations and attitudes about hiring youth with I/DD, and forming relationships with businesses would be important to finding and creating job opportunities for youth with I/DD. States employed a variety of methods to engage businesses, which included meeting with employers through Community Conversations. Community Conversations use an adaptation of the World Café method to engage youth with $\mathrm{I} / \mathrm{DD}$, family members, educators, employers, and other community members in round table discussions on topics related to CIE for youth and young adults with I/DD (World Café, 2016). Tennessee and Wisconsin were the first two PIE states that used this strategy and California's Local Employment Collaborative Teams (LECTs) later adopted and implemented Community Conversations. Other methods included creating formal partnerships between businesses and state organizations, collecting employer surveys, conducting trainings on how to engage employers, and developing resources for employers hiring youth with I/DD. The section below highlights how Alaska and Missouri employed some of these methods.

\subsubsection{Creating formal partnerships between busi-} nesses and local organizations in Alaska and Missouri. Several states leveraged partnerships with businesses and state or local organizations to improve business engagement. For example, Alaska's consortium, AIEI, facilitated the creation of the Business Employment Services Team (BEST), an interdepartmental business engagement team between the state Department of Labor and Workforce Development and Department of Health and Social Services. BEST's goal is to improve hiring for individuals with disabilities and veterans and help serve state business needs. BEST has held monthly events including trainings to promote employer engagement. In February 
2016, BEST hosted the annual Employment First Job Fair with 1,146 job seekers and 85 employers in attendance.

Additionally, Missouri's consortium titled ShowMe-Careers leveraged partnerships with the Business Leadership Network of Greater Kansas City (BLNGKC), the Kansas City Nexus, Add-Us-In Kansas City, and local business groups to improve business partnerships. The Show-Me-Careers Pilot Communities partnered with local business leaders such as the City Manager and the local Chamber of Commerce to host business roundtable discussions, and school districts created a shared employer database. The Show-Me-Careers Pilot Communities also received training and technical assistance to support the development of employer-driven partnerships. Since the beginning of the partnership, the BLN-GKC established at least four initiatives to engage local businesses in support of disability inclusion in employment. At the state level, strategies included obtaining funding from the Developmental Disabilities Council for the BLN-GKC to develop a web-based Business Resource Toolkit and a foundation grant to implement KC@ Work. KC@ Work later developed a partnership with a local business to train four individuals, and continued to engage additional employers.

\subsubsection{Self-advocate and youth engagement efforts}

Each PIE consortia also engaged individuals with I/DD to ensure that their state systems change efforts were informed by the opinions of those with I/DD, since they would directly benefit from the consortia's efforts. Alaska, Iowa, Mississippi, Missouri, and Wisconsin facilitated Take Your Legislator to Work Day, where state legislators attended the workplace of a youth employee with I/DD to learn about the youths' employment experiences firsthand. Youth also frequently participated as members of states' consortia. Mississippi in particular encouraged young adults to participate in leadership councils and present at several statewide conferences, including the state disAbility MegaConference. TennesseeWorks hosted an annual Think Employment! Summit, in which students with disabilities, their families, and service providers participated in policy, provider, or selfadvocate-focused sessions.

\subsubsection{Leveraging connections to connect with} youth in Alaska and New York. Alaska and New York both leveraged connections with external groups to connect with self-advocates and promote selfadvocacy efforts across the states. In Alaska, AIEI engaged youth through Peer Power Alaska, a selfadvocacy organization. A group advisor was hired for Peer Power Alaska in 2013, and, as of September 2016, group membership included more than 100 youth from 14 cities in Alaska. In 2016, the group hosted informational tables at five job fairs across the state and co-sponsored a Youth Job Fair with the Governor's Council on Disabilities and Special Education that had 46 businesses and 63 youth in attendance.

In New York, NYS PIE worked with the SelfAdvocates of NYS (SANYS) and Independent Living Centers in Western New York to engage youth with I/DD. During the 2012-2013 academic year, members of NYS PIE, SANYS, and the Independent Living Centers developed and piloted a training program in Western New York. This program included three inperson youth self-advocate summits with more than 100 students. Another region of the state hosted a self-advocacy summit in 2013 with 70 youth, family members, teachers, and professionals. A SANYS representative noted that participating in NYS PIE led the organization to "focus more on youth employment and become a partner on several initiatives across the state."

\subsection{Infrastructure}

Even in the right contexts, with the components and connections for systems change in place, change may not readily occur without robust policies, trained professionals, shared data systems, and other investments that support the necessary infrastructure. A robust infrastructure supports the coordination of employment services, provides support to those seeking services, streamlines service delivery, and ensures quality management. However, PIE consortia identified a lack of policies, continued investments, and readily available, meaningful, and uniform data across their state systems as a challenge. In response, states participated in numerous projects to improve existing infrastructure and create new data driven solutions to better assist service providers, families, self-advocates, and other stakeholders. For example, California engaged in data sharing to develop the California Data Dashboard, while New York engaged in reporting activities to ensure that the state tracked and embedded Project SEARCH ${ }^{\mathrm{TM}}$ outcome data into the New York Employment Services System (NYESS), a state employment outcomes data initiative. Tennessee also worked to include data from additional 
state agencies in existing data systems. Alaska's consortium, AIEI, collaborated with the Alaska Mental Health Trust Authority (Trust) to establish an employment initiative and secure continued investment from the Trust in employment programs and systems. For example, AIEI sought seed funding from the Trust to create a Disability Benefits 101 calculator to provide resources to individuals with I/DD and their families seeking to understand the services available to them, and Iowa created an Employment and Disability Snapshot Report after testing collection methods and data points in a pilot project. Wisconsin's consortium also partnered with the state's Protection and Advocacy Organization to create a subminimum wage electronic data collection system. The sections below illustrate examples of states' activities related to creating common access points to data, and creating interactive, online resources for individuals with I/DD and other stakeholders. Consortia activities to improve their state infrastructure fall under the PIE objective Implementing Strategies and Exploring and Scaling-Up Promising Practices to Improve CIE Outcomes.

\subsubsection{Common data sources and displays}

A key challenge that states acknowledged early in the grant was the lack of common data sources on certain key disability employment-related metrics. In particular, consortia identified that when collecting these metrics, state agencies did not share information with each other and did not agree on common metric definitions. As a result, there was also no single access point for advocates and other consumers interested in viewing the information. Therefore, a critical role of the consortia work to support shared data systems was supporting collaboration to reach a shared understanding of employment terms and outcomes. Efforts to reach a shared understanding between entities also supported building cross-agency collaboration.

In response to the lack of common data sources, Alaska, California, Iowa, Missouri, New York, Tennessee, and Wisconsin either developed their own data systems or worked to improve already existing systems. The section below highlights California's work to establish a Data Dashboard to improve data compatibility between state agencies, and provide a single access point for stakeholders seeking data for advocacy or other uses.

\subsubsection{California's Data Dashboard. California's} PIE consortium, CECY, created a Data Dashboard with the help of its Data Nerds Workgroup. The dashboard monitors the state's progress in employing youth and young adults with I/DD across the state. Specifically, it provides up-to-date data on measures of progress, such as the wage gap between individuals working in CIE and individuals working in groups in the Support Employment Program through the state's Regional Centers, which provide services to individuals with I/DD. Other metrics shown on the Data Dashboard include California's employment rate for individuals with I/DD compared to those without a disability, and secondary education outcomes for individuals with significant disabilities. The Data Dashboard, which is located on California's State Council on Developmental Disabilities' (SCDD) website, experienced consistent usage, and quickly became an important part of the SCDD website (California State Council on Developmental Disabilities, 2016). It is one of the top ten most-visited pages on the website and averaged 222 monthly views as of September 2016. Additionally, CECY members cited the Data Dashboard as a valuable resource in advocacy and legislative outreach work, since it shows tangible outcomes and statistics that advocates can use to support their positions. Due to the widely positive feedback from CECY members, the SCDD committed to sustaining the Data Dashboard beyond the end of PIE grant funding.

\subsubsection{Creating tools and resources for individuals with $I / D D$, their families, and educators}

Other states focused efforts on creating tools for use by youth and young adults with I/DD and other stakeholders. These tools increase access to a single, consolidated source of employment information and resources.

\subsubsection{New York's MyPathNY.org interactive tool.} MyPathNY.org is an interactive online tool that provides a single source of information and connections to services and supports for individuals in New York seeking employment (New York State Partnerships in Employment, 2016). The content NYS PIE produced for the website includes resources on eligibility for Adult Career and Continuing Education Services-Vocational Rehabilitation (ACCES-VR) and OPWDD services, and job readiness tools. The website also features content developed for the New York State Commission for the Blind and the development of accessibility features for visually impaired site users. 
To develop the website, NYS PIE worked to find and generate material for the tool, and market the tool to stakeholders. NYS PIE members provided demonstration presentations and webinars to three regional groups providing transition services, two provider agencies, one Parent Center, two Transition Conferences, and the New York State Rehabilitation Association. Additionally, members of NYS PIE developed a MyPathNY.org pocket folder and a version of the folder in Braille for distribution by schools to market and support use of the website. This folder, which includes a guide on how to use the website, and a glossary of useful terms, accompanies the web platform and provides space to store printed copies of all the reports generated by the website. Six school districts and three provider agencies requested school classroom sets of these folders, and, 1,900 folders have been distributed as of September 2016. After receiving positive feedback from MyPathNY.org users and NYS PIE leadership, NYS PIE leadership and project partners expressed interest in sustaining MyPathNY.org after New York's PIE funding ends.

\subsubsection{Alaska's Disability Benefits 101 calculator} resource. Alaska identified a concern raised by individuals with I/DD and their families was that youth would lose benefits if they worked. To respond to this concern and clarify misconceptions, AIEI recommended that Alaska's Mental Health Trust Authority invest seed money into the creation of the Disability Benefits 101 online calculator, which would provide customized information on how employment is compatible with eligibility for benefits in Alaska. Due to AIEI's strong advocacy work and relationships, the Alaska Mental Health Trust Authority agreed to fund the calculator, and the State Independent Living Council (SILC) agreed to fund maintenance costs for the first year. Working with both the Alaska Mental Health Trust Authority and SILC, AIEI completed initial information requests with this development team and met with subject matter experts on Medicaid, Social Security, and Vocational Rehabilitation. AIEI also held three feedback sessions with stakeholders, which included advocates and families. After launching the website in 2016, AIEI provided training in three Alaska cities along with a distance delivery training option, or virtual training, as part of AIEI's commitment to engage individuals in all regions of the state's large geographic area (World Institute on Disability, 2016).

\subsection{Scale or Sustainability}

Within each of the previous focus areas of Context, Components, Connections, and Infrastructure, states pursued activities aimed at scaling-up and sustaining best practices. The Scale or Sustainability focus area addressed all four PIE objectives to ensure a comprehensive system was available to all youth and young adults with I/DD to produce lasting, broad, and inclusive CIE outcomes. The federal funding to support the development of the consortia has fostered relationships that will exist beyond the grant and established permanent changes to policy and infrastructure. States also identified opportunities to leverage existing or future grants to support activities of the PIE Projects. In addition, states developed project websites or used state agency websites, and relied on project e-mail listservs to disseminate information. Even if consortia do not regularly update information in the future, the information produced during the grant and shared on the project websites will exist beyond the grant. States also reported that grant activities have been embedded into the work of individual agencies.

Federal funding for six of the eight grantees ended in September 2016 and the other two states will receive funding through September 2017. Of the states ending in 2016, four states requested and received a no-cost extension to convene additional consortium meetings. With various end dates, states were at different stages of planning for and implementing plans for sustainability. As of September 2016, all states held discussions on which types of collaboration and activities would continue after the grant period and shared project highlights and best practices with stakeholders.

\subsubsection{Establishing and maintaining relationships}

States identified that any scale or sustainability efforts require strong cross-system and cross-agency relationships. A major challenge faced by all states is turnover of staff at the state level, including agency leadership, as well as at the community level, including educators and service providers. States are faced with ensuring that these relationships and partnerships remain in place regardless of funding and staff or leadership turnover. Each consortium was faced with the challenge that many of the partners and systems did not traditionally communicate with one another. The consortia meetings were an opportunity to enhance communication and collaboration 
between these partners and establish a clear vision to achieve a common goal. Through these meetings, states developed strong partnerships with state agencies and other entities that will exist beyond the project.

\subsubsection{Establishing formal Memorandum of} Understanding or Memorandum of Agreement. State consortia coordinated efforts with other entities with which the consortium members had longstanding collaborative relationships that were either informal or formally established through a signed Memorandum of Understanding (MOU) or Memorandum of Agreement (MOA). The PIE Project request for proposals required each consortium to submit a signed MOU or MOA between, at a minimum, the state's Developmental Disabilities Agency, Vocational Rehabilitation Agency, State Education Agency, and State Developmental Disabilities Council. States also included other partners in the MOU, such as Division of Workforce Development, a University Center for Excellence in Developmental Disabilities, self-advocates, Protection and Advocacy System, and other non-profit organizations. The specific partners and lead entities varied by state, with a University Center for Excellence in Developmental Disabilities serving as the lead entity in four states, and the State Developmental Disabilities Council in the remaining four states.

These MOU or MOA allowed states to bring the appropriate level of leaders to consortia meetings that could make decisions, initiate systems change efforts, and advocate for change within their respective agencies. By identifying these partners prior to receiving grant funding, states were able to begin work immediately. Additional partners, not included in the original MOU or MOA, also joined the consortia to move the state forward with improving CIE. In addition to the original MOU required for the grant application, states identified existing or new MOU or MOA between other partners. To increase collaboration and coordination of state services, California, Iowa, Mississippi, Missouri, and Tennessee established MOUs and MOAs between state departments. Alaska and New York have also continued to support the development of MOUs. States identified that the commitment from administrative level leadership and other key partners was necessary for meeting long-term systems change goals.

3.5.1.2. Maintaining existing relationships. States recognized that interagency collaboration is an essen- tial component for creating systems change and it is helpful to have an agreement of the roles and responsibilities of each partner. Prior to considering how to scale or sustain any activity, the state consortia established relationships with key partners and then identified which agency or member would continue the work in the short-term and possibly beyond the grant. For example, in California, the consortium held a two-day planning meeting a year before the end of the grant to identify which members would be responsible for specific activities. The in-person meetings resulted in the development of a 2015-2016 Strategic Implementation Plan and Draft Continuity Plan for potential work to consider after the end of the grant. Each CECY Workgroup also contributed to a Dissemination Planning document that summarized how each consortium product would be sustained, updated, and disseminated after the grant ends. California consortium members also contributed to the development of the California Competitive Integrated Employment Blueprint, which set a precedent for four California agencies to collaborate beyond the grant. Through consortium meetings, states developed strong partnerships with state agencies and other entities. All states acknowledged that the PIE grant has resulted in strong crossagency relationships that did not exist before the project.

\subsubsection{Scaling-up promising practices}

PIE consortia held discussions around sustainability and continuation of PIE activities beyond the project. Sustainability plans included identifying strategies to engage consortium members, monitoring the effectiveness of best practice models, and assessing the availability of agency funding to sustain project activities. In addition, PIE statewide demonstration projects increased employment opportunities for youth and young adults with I/DD at the local level. Several states, including Alaska and Wisconsin, are using existing institutions and state initiatives, such as the Alaska Mental Health Trust Authority and the Wisconsin TIG and Wisconsin PROMISE grant, to ensure that project activities continue. Alaska is collaborating with several partners to explore the use of distance delivery training as an innovative approach to capacity building in rural and remote regions of the state. States also adopted alternative certificates and diplomas for individuals with disabilities that place an emphasis on employment. In addition, state consortia assisted with trainings and increasing employer awareness and understanding of 
these alternative certificates and diplomas that will continue beyond the grant.

\subsubsection{Leveraging and braiding existing grants or} initiatives. The PIE states each have a long history of collaborative efforts to increase employment of individuals with disabilities. For example, states engaged in the EFSLMP initiative awarded prior to PIE in Iowa and Tennessee, and during PIE in Missouri and New York. States also had I/DD agency membership in the SELN prior to PIE in Iowa and Missouri, and during PIE in New York. As a result, states identified existing grants and initiatives that they can use to continue the activities started during the PIE Project.

During the final consortia meetings in the six states ending in September 2016, consortia members discussed the value of continuing cross-agency collaboration. All states identified the benefit of continuing this work and held preliminary discussions about which agency would host and facilitate the work of the consortia moving forward. In Iowa, the consortium leadership team, ICIE Core Team, and project staff were establishing the ICIE as a 501(c)3 non-profit organization. States also considered how to expand this work to all individuals with disabilities, not just youth and young adults. In Missouri, members of the Show-Me-Careers leadership consortium planned to sustain activities through the Missouri SELN Leadership Team. Each agency serving on the Missouri Show-Me-Careers consortium identified a representative to serve on the Missouri SELN Leadership Team starting in November 2016. The focus of this new group will be on promoting integrated employment for individuals with disabilities and will expand its focus to address the needs of adults as well as youth with I/DD.

States have also replicated PIE promising practices in other state initiatives, including embedding PIE practices into other grants or expanding promising practices from the PIE statewide demonstration projects to other sites. In Wisconsin, the LGTW high school statewide demonstration sites used a coaching model to support youth with I/DD. The Wisconsin TIG and PROMISE grant adopted the Wisconsin LGTW coaching model and parent trainings. At state leadership meetings, consortium meetings, and regular state and national presentations, LGTW consortium leadership highlighted that the LGTW coaches were one of the main reasons the school sites were successful at increasing employment outcomes. Several Wisconsin LGTW pilot sites served as mentors for other school districts. In addition to sharing best practices with other school districts in Wisconsin, school districts in Mississippi and Missouri were interested in the best practices from the school-based demonstration sites. The two Mississippi school districts participating in the demonstration developed materials to share best practices with other schools. The Mississippi Council on Developmental Disabilities will disseminate the manuals or guides to support implementation across the state.

\subsubsection{Embedding employment language into pol-} icy recommendations. States enacted policy and legislative changes to support employment that will continue beyond the grant. States are also looking at cross-disability legislation and policy work to include the entire disability community. States recognized that policy change required incremental steps to achieve broader goals. State consortia developed resources, shared success stories of individuals with I/DD working in competitive integrated jobs, presented data on demonstration site employment outcomes, and taught individuals with disabilities how to advocate for policy change. Consortia members also testified for policy change and presented recommendations to agency leaders that focused on employment for youth and young adults with I/DD. In Wisconsin, the LGTW Policy Team pursued several strategies to ensure funding and legislation for activities that support CIE. For example, the consortium engaged youth through the Youth Track at LGTW Consortium meetings that focused on self-advocacy specific projects. LGTW's Policy Team and leadership from the Department of Public Instruction (DPI) also held regular meetings to discuss recommendations for DPI's improvement plans around Results Driven Accountability, which the U.S. Department of Education Office of Special Education Programs required for all states. LGTW recommendations resulted in DPI focusing on a broader age range of reading skills for improvement and conducting an analysis of reading's effect on readiness for college and employment. One of LGTW's job coaches served as the Statewide Transition Specialist for DPI, allowing some of LGTW's past recommendations related to post-secondary education and the transition process to be revisited. In addition to Wisconsin, Tennessee consortium members prepared comments and suggested revisions to the state's proposed revised and new Medicaid Waivers and HCBS Statewide Transition Plan to be more employment-focused and better aligned with the national movement away from facility-based 
services towards home and community-based services. Tennessee's HCBS Statewide Transition Plan included the recommended employment language and was approved in April 2016.

Between October 2011 and September 2016, PIE states developed strong partnerships among state agencies, self-advocates, and other entities to continue the project work, established the infrastructure necessary for improved data sharing and employment resources, and enacted policies to support employment as the first and preferred option for individuals with I/DD.

\section{Discussion}

Through the PIE Projects, eight states identified success stories of youth and young adults with I/DD seeking and obtaining CIE. By sharing these success stories and resources on employment with legislators and agency leaders, the state consortia were able to inform state and agency policy to include Employment First language. Across all states, consortia members identified strengthened relationships as a key outcome of the project work. Although many of these members had worked together on collaborative initiatives before the PIE Project, the structure of the consortia, with an independent entity leading the effort, created a neutral meeting space for all members to share their opinions and develop a strategic vision for changing the state system to support CIE. Since systems change often takes many years to see the intended impact, the results from this project only highlight short-term outcomes, with the long-term impact of this project yet to be seen. At a minimum, each state has laid a foundation to support future work towards improving employment outcomes for youth and young adults with I/DD. States have also considered how to expand this work to all individuals with disabilities, not just youth and young adults.

At the beginning of any systems change project, it is difficult for states to identify future legislation or initiatives that will impact their project work. Due to these outside activities, the PIE states often changed direction to focus on including employment language in new legislation or other policies, such as the consortia supporting the transition to Medicaid managed care in Iowa and Tennessee. As policies changed, the consortium meetings and materials served as a constant resource for updating state leaders, educators, employers, individuals with I/DD, and family members. The ability of the consortia leadership to adapt to the changing environment and provide needed resources to consortia members was critical to informing state policy and increasing awareness of employment opportunities. During the five-year PIE Project, the WIOA was enacted at the federal level and all states pursued activities to implement the legislation at the state level. Several states credited the PIE Project with helping to lay the foundation that supported a seamless transition for their state agencies to implement WIOA. State consortia members identified that consortia meetings were critical to increasing awareness and understanding of various employment topics.

A limitation to the data collected by The Lewin Group is that data on individual employment outcomes was only available for a subset of the state and was not representative of the entire state. These pockets of excellence identify individuals with I/DD employed at a point in time but the data does not track longitudinal outcomes beyond that six-month reporting period. Another limitation to national and state employment data for individuals with I/DD is that data reports are often delayed by several years. This article focuses primarily on systemic qualitative data and additional research is needed to track longitudinal employment outcomes at the individual level.

\section{Conclusion}

Several promising practices, policies, relationships, and programs emerged within each of the five focus areas that support and drive CIE opportunities for youth and young adults with I/DD. Through the PIE Project, the AIDD has enhanced collaboration across state systems to improve employment outcomes for youth and young adults with I/DD. Each consortium used a combination of approaches and strategies from the five focus areas to account for state, regional, and local variations in culture and available infrastructure and resources, including available funding and staff time. The PIE Projects enabled states to establish cross-system and cross-agency relationships and develop the infrastructure needed to support CIE for youth and young adults with I/DD. Following this grant, each of the eight states will continue to work towards improving the state employment systems. In addition to WIOA legislation supporting cross-agency collaboration, the AIDD awarded funding in 2016 to six additional PIE states to continue cross-agency collaboration-District of Columbia, Hawaii, Ken- 
tucky, Massachusetts, South Carolina, and Utah. The new PIE states and other states interested in improving competitive integrated employment opportunities can apply the lessons learned and outcomes from these eight PIE states to advance systems change within their state.

\section{Acknowledgments}

The Lewin Group developed the contents of this article with funding provided by the U.S. Department of Health and Human Services, Administration for Community Living, Administration on Intellectual and Developmental Disabilities under the Process and Systems Change Evaluation of Partnerships in Employment Systems Change Grants (Contract HHSP23320095639WC Task Order HHSP23337017T). The Lewin Group evaluation team would like to thank Anita Tonakarn, Caitlin Maloney, and David Fialkow for their support. The ideas, opinions, and conclusions expressed are those of the authors and do not represent recommendations, endorsements, or policies of the Administration on Intellectual and Developmental Disabilities.

\section{Conflict of interest}

None to report.

\section{References}

Butterworth, J., Winsor, J., Smith, F. A., Migliore, A., Domin, D., Ciulla Timmons, J., \& Hall, A. C. (2015). StateData: The national report on employment services and outcomes. Boston, MA: University of Massachusetts Boston, Institute for Community Inclusion. Retrieved from https://www.statedata.info/

California State Council on Developmental Disabilities. (2016). State of California Developmental Disabilities System Employment Data Dashboard. Retrieved from http://www.scdd.ca.gov/employment_data_dashboard/

Carter, E. W., Austin, D., \& Trainor, A. A. (2012). Predictors of postschool employment outcomes for young adults with severe disabilities. Journal of Disability Policy Studies, 23(1), 50-63.

Coffman, J. (2007). A Framework for Evaluating Systems Initiatives. Retrieved from http://www.buildinitiative.org/ WhatsNew/ViewArticle/tabid/96/ArticleId/621/Frameworkfor-Evaluating-Systems-Initiatives.aspx
Erickson, W., Lee, C., von Schrader, S. (2016). Disability Statistics from the American Community Survey (ACS). Ithaca, NY: Cornell University Yang-Tan Institute (YTI). Retrieved from Cornell University Disability Statistics website www.disabilitystatistics.org

New York State Partnerships in Employment. (2016). My Path NY. Retrieved from http://www.mypathny.org/

Public Law. (2014). H.R. 803 - 113th Congress: Workforce Innovation and Opportunity Act. Section 404 (5). Retrieved from https://www.congress.gov/bill/113th-congress/housebill/803/text

Scientific Software Development GmbH. (2016). ATLAS.ti [computer software]. Berlin.

Statedata.info. (2016). State IDD Agencies. U.S. Total: Integrated employment percentage. Retrieved from http://www.statedata. info/data/showchart/452419

Tennessee Student Assistance Corporation. (2016). Tennessee STEP UP Scholarship. Retrieved from https://www.tn.gov/ collegepays/article/tennessee-step-up-scholarship

Test, D., Fowler, C., Richter, M., White, J., Mazzotti, V., Walker, A., Kohler, P., \& Kortering, L. (2009a). Evidence-based practices in secondary transition. Career Development for Exceptional Individuals, 32, 115-128.

Test, D., Mazzotti, V., Mustian, A., Fowler, C., Kortering, L., \& Kohler, P. (2009b). Evidence-based secondary transition predictors for improving post-school outcomes for students with disabilities. Career Development for Exceptional Individuals, 32, 160-181.

The Arc. (2015). WIOA: What it means for people with intellectual and/or developmental disabilities (I/DD). National Policy Matters. Retrieved from http://www.thearc. org/document.doc?id=5183

U.S. Department of Labor Office of Disability Employment Policy. (2016). Disability Employment Policy Resources Employment First. Retrieved from https://www.dol.gov/ odep/topics/EmploymentFirst.htm

University of Missouri Kansas City Institute for Human Development, University Center for Excellence in Developmental Disabilities. (2016). LifeCourse Tools. Retrieved from http://www.lifecoursetools.com/planning/

Vanderbilt Kennedy Center for Excellence in Developmental Disabilities. (2016). TennesseeWorks Employment and Disability by the Numbers. Retrieved from http://www.tenn esseeworks.org/data-dashboard/

Wisconsin Board for People with Developmental Disabilities. (2016). Let's Get to Work Quick Guide on Transition to Employment. Retrieved from http://www.letsgett oworkwi.org/index.php/lgtw-resource-guide/

World Café. (2016). World Café Method. Retrieved from http://www.theworldcafe.com/key-concepts-resources/worldcafe-method/

World Institute on Disability. (2016). Alaska Disability Benefits 101. Retrieved from https://ak.db101.org/ 